\title{
The nature and quality of the mathematical connections teachers make
}

\author{
Authors: \\ Michael K. Mhlolo ${ }^{1}$ \\ Hamsa Venkat ${ }^{2}$ \\ Marc Schäfer ${ }^{1}$ \\ Affiliations: \\ ${ }^{1}$ Mathematics Education \\ Department, Rhodes \\ University, South Africa \\ ${ }^{2}$ Marang Centre for \\ Mathematics and Science \\ Education, University of the \\ Witwatersrand, South Africa \\ Correspondence to: \\ Mike Mhlolo \\ Email: \\ m.mhlolo@ru.ac.za \\ Postal address: \\ PO Box 94, Grahamstown \\ 6140 , South Africa \\ Dates: \\ Received: 21 July 2011 \\ Accepted: 14 Mar. 2012 \\ Published: 16 May 2012 \\ How to cite this article: \\ Mhlolo, M.K., Venkat, H., \\ \& Schäfer, M. (2012). The \\ nature and quality of the \\ mathematical connections \\ teachers make. Pythagoras, \\ 33(1), Art. \#22, 9 pages. \\ http://dx.doi.org/10.4102/ \\ pythagoras.v33i1.22
}

C 2012. The Authors. Licensee: AOSIS OpenJournals. This work is licensed under the Creative Commons Attribution License.
Current reforms in mathematics education emphasise the need for pedagogy because it offers learners opportunities to develop their proficiency with complex high-level cognitive processes. One has always associated the ability to make mathematical connections, together with the teacher's role in teaching them, with deep mathematical understanding. This article examines the nature and quality of the mathematical connections that the teachers' representations of those connections enabled or constrained. The researchers made video recordings of four Grade 11 teachers as they taught a series of five lessons on algebra-related topics. The results showed that the teachers' representations of mathematical connections were either faulty or superficial in most cases. It compromised the learners' opportunities for making meaningful mathematical connections. The researchers concluded by suggesting that helping teachers to build their representation repertoires could increase the effectiveness of their instructional practices.

\section{Introduction}

Developed and developing countries, including South Africa, have revised their mathematics curricula in recent years to take account of what they regard as the knowledge and skills learners require to participate in a globalising twenty-first century world.

There seems to be some agreement that higher order cognitive skills and processes are necessary for more equitable educational outcomes and economic productivity (Muller \& Subotzky, 2001).

However, the major challenge has been how to convert this noble vision from the written into the taught curriculum.

\section{The problem}

In South Africa, there has been general public discontent about learners' actual gains in knowledge and skills despite the steady increase in pass rates since the advent of democracy. Muller (2005) questioned the credibility of senior certificate pass rates given the opinion that standards have actually dropped:

The largely invisible outcome, invisible to school educators, that is though not invisible to employers or university admission officers, was that the schooling system was emitting a cohort or two which had reduced opportunities to demonstrate higher-level cognitive skills, had possibly not even been taught them and, in far too many cases, therefore did not have them. (p. 43)

This quotation raises two critical concerns:

- that standards have actually dropped despite the upward trend in pass rates

- that low-level cognitive skills were intentional or unintentional threats to the social and economic health of the nation.

Lolwana (2005) and Edwards (2010) made similar observations about the low cognitive demand of mathematical activities and recommended that researchers do more to understand the specific cognitive levels in the intended, the tested and the implemented curriculum.

It is from these observations and recommendations that the researchers saw a potential gap in knowledge. With specific reference to classroom practices (the implemented curriculum), this article raises the question of the extent to which high school mathematics teachers are creating opportunities for learners to acquire cognitively demanding mathematical connections to use in problem solving situations.

The researchers' entry point to this is by conceptualising mathematical understanding. Whilst acknowledging that there is no consensus about the meaning of 'understanding', Barmby, Harries, Higgins and Suggate (2009) suggest three perspectives that the researchers found relevant for taking their ideas forward. 
Barmby, Harries, Higgins and Suggate (2009) argue that one shows a deep understanding of mathematics through:

- connections made between different mathematical ideas

- different representations of mathematical ideas

- reasoning between different mathematical ideas.

They suggest that 'in order to examine someone's understanding of a mathematical concept, it is important that we examine the connections that a person makes to that concept ...' (pp. 5-6).

\section{Conceptualising a mathematical connection}

However, what exactly is a mathematical connection?

Blum, Galbraith, Henn, and Niss (2007) suggest that the literature has identified two major types of mathematical connections. The first is recognising and applying mathematics to contexts outside of mathematics (the links between mathematics, other disciplines or the real world). The second concerns the interconnections between ideas in mathematics.

Most articles in the literature focus on connections in the real world and do not explore the area of mathematical connections or interconnectedness within mathematics (Businskas, 2008). However, learners' ability to make connections in mathematics itself is crucial for conceptual understanding (Anthony \& Walshaw, 2009b) as well as for application outside the discipline. This study aims to contribute to the area of interconnectedness within mathematics.

One can define a mathematical connection broadly as:

- a relationship between ideas or processes that one can use to link topics in mathematics

- a process of making or recognising links between mathematical ideas

- an association a person might make between two or more mathematical ideas

- a causal or logical relationship or interdependence between two mathematical entities (Businskas, 2008).

The literature has often captured these broad views into three ways of considering mathematical interconnectedness:

- as a feature of mathematics (a priori - implying that it exists independently of the learner)

- as a relationship that the learner constructs

- as a process that is part of the activity of doing mathematics.

This article concentrates on the first and last views. The researchers note the importance of the ability of learners to recognise mathematical connections (Hodgson, 1995). However, we concur with Weinberg (2001), who argued that, whilst learners might make connections spontaneously, one cannot assume that they will make them without some intervention.

One should make learners aware of different possible mathematical connections. Teachers play a crucial role in this intervention because they must teach lessons in ways that will enable learners to recognise and make sense of these mathematical connections.

Therefore, the view of the researchers is that considering mathematical connections as features (a priori) that exist independently of the learner would enable them to judge the process (whether or not the teacher was creating opportunities for learners to recognise them). Therefore, the researchers' next challenge was to develop a workable framework for classroom observations to enable them to examine how teachers structured learners' opportunities for making appropriate mathematical connections.

\section{A framework for thinking about mathematical connections in practice}

The researchers borrowed from Businskas (2008). In her study, she posed the question: What are the characteristics of the explicit mathematical connections that teachers are able to articulate from their practice? Following the analyses she made of teachers' responses to her study, she proposed a framework for identifying mathematical connections in practice. Her model has the five categories that follow:

- different representation (DR) as a form of mathematical connection

- part-whole relationships (PWR)

- connections where A implies B (IM)

- connections that show that $\mathrm{A}$ is a procedure for doing $\mathrm{B}(\mathrm{P})$

- instructional orientated connections (IOC) that show how certain concepts are pre-requisites for understanding related concepts.

These five types of mathematical connections became the reference point for trying to understand the nature and quality of observed instructional strategies in selected South African Grade 11 classrooms. Whilst Businskas (2008) only identified possible mathematical connections in practice, this study extended this focus because the interest of the researchers was also to identify and analyse the quality of these connections in practice (i.e. to link connections to their cognitive strengths or cognitive demands).

\section{Our focus: Different representations}

Whilst the five categories provided the framework for the researchers' broader study, the focus in this article is on different representations as types of connections. Barmby et al.'s (2009) second view of mathematical understanding guided this decision to some extent.

The ability to present a concept in several ways shows a deep understanding of that concept. There is a view in the literature that recognising and producing alternate representations is a particularly fruitful way of conceptualising what a mathematical connection is (Gagatsis \& Elia, 2004) and that the transformation between these representations is a useful way of assessing whether learners are making connections (Reead \& Jazo, 2002). The pedagogical implication is that 
teachers should use several modes of representation to improve learners' understanding of mathematics and that these representations should be accurate and appropriate (National Council of Teachers of Mathematics, 2000).

Therefore, the researchers decided to focus on different representations. An important finding in a broader study (Mhlolo, 2011) also guided them. It showed that different representations were more prevalent than the other types in all 20 lessons that the researchers recorded (see Figure 1).

These results seem consistent with earlier classroom observations elsewhere. They showed that teachers constantly engage in a process of defining and constructing a mental image of some mathematical object and use instructional representations in the process (Businskas, 2008; McDiarmid, Ball \& Anderson, 1989; Stylianou, 2010).

\section{Teacher's representations of connections}

Interpreting a mathematical connection as a recognition of two or more alternate representations lies at the intersection of research into mathematical connections and research into representations (Businskas, 2008). In this intersection, the term 'different representation' could mean a mathematical connection (object) or the ways teachers present the mathematical idea (activity or process). The researchers use both of these interpretations in this article and felt that they had to clarify their position about using these terms.

In this article, the researchers use the term 'different representations' (DR) in accordance with Businskas' (2008) definition to refer to an inherent feature of mathematics (object) - links, relationships or mathematical connections. These relationships exist inherently in mathematics, regardless of whether teachers or learners recognise them. Businskas posits that this (DR) category comprises the two subcategories that follow.

$\mathrm{A}$ is an alternate representation of $\mathrm{B}$, where the two representations (A and $\mathrm{B}$ ) of a mathematical concept or idea come from any two of the following modes - symbolic (algebraic), graphic (geometric), pictorial (diagrammatic),

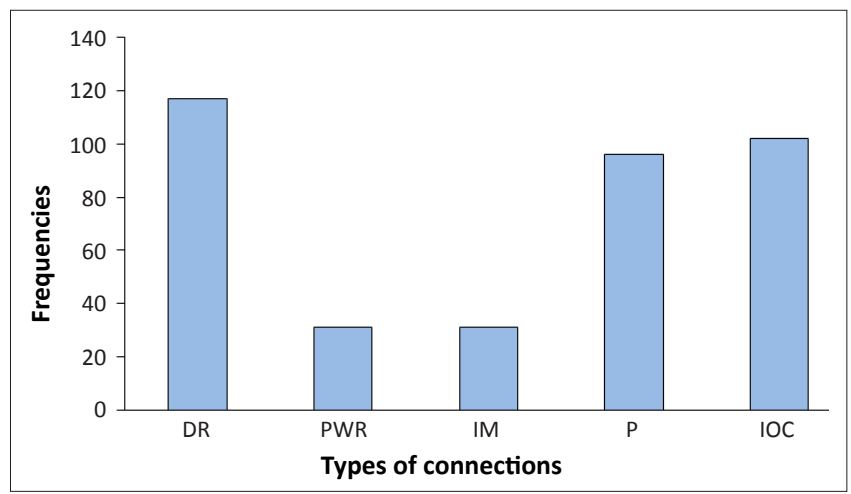

$D R$, different representations; PWR, part whole relationships; IM, connections where $A$ implies B, P, procedural connections; IOC, instructional oriented connections.

FIGURE 1: Summary of data counts for all four teachers in different categories. manipulative (physical object), verbal description (spoken), or written descriptions. For example, the graph of a parabola (graphic or geometric) is an alternate representation of $f(x)=a x^{2}+b x+c$ (symbolic or algebraic).

$\mathrm{A}$ is an equivalent representation of B, where 'equivalent' distinguishes between alternate representations and refers to concepts that are connected by representing them in different ways using the same mode of representation. One example is $13+12$ equals 25 and $f(x)=a x^{2}+b x+c$ equals $f(x)=a(x-p)^{2}+q$. Another example is defining concepts by rephrasing verbal representations or written representations using different descriptors.

On the other hand, one uses the term 'representation' to refer to an activity or process (the teacher's way of presenting, or the teacher's didactic strategy of converting, inherently linked or connected mathematical ideas). In this sense, a teacher can 'represent' an alternate link or an equivalent link, a part-whole relationship or any other similar mathematical connection.

Empirical evidence suggests that this activity of representing is a core activity of teaching mathematics (Ball, 2001) because the ways teachers represent mathematical ideas are fundamental to how people understand and use those ideas.

The focus of this article is the quality of teachers' representations of mathematical connections. Therefore, a question captures its next challenge: How can we begin to judge the quality of the alternate or equivalent representations (links) the teacher presents in a classroom situation?

\section{Our conceptualisation of quality in teachers' representations}

The third view of Barmby et al. (2009) on mathematical understanding guided the researchers as they tried to determine the strengths or quality of teachers' didactic strategies. It links connections and the reasoning between them. According to Sierpisnka (1996), acts of understanding link what one must understand with the 'basis' or 'reasoning' for that understanding.

'Basis' and 'reasoning' suggest answering the deeper questions of 'why or how we know'. Andrews (2009) combined these notions when he argued that teachers' representations of mathematical connections, which (1) articulation, justification and argumentation from the teachers and/or (2) pressing for this reasoning from the learners accompanied, could lead learners into acquiring a deeper understanding of knowledge and skills.

Anthony and Walshaw (2009a) had a similar view as they posited that effective teachers encourage their learners to explain and justify their solutions. They ask learners to take and defend their positions against the mathematical claims of other learners. This causes their attention to shift from procedural rules to making sense of mathematics because learners try less to find the answers and more to discover the thinking that leads to the answers. 
According to Squires (2009), the Trends in Mathematics and Science Studies (TIMSS) reports also show that teachers, in the countries that performed well, placed greater cognitive demands on learners by encouraging them to focus on concepts and their connections. The teachers in these countries maintained this cognitive demand when they insisted on justifications, explanations and meanings through questioning or other feedback (Zurawsky, 2006). The findings from these studies also showed that, in classrooms in which teachers set instructional tasks and learners executed them at high levels of cognitive demand, the learners achieved better on measures of reasoning and problem-solving than did learners in classrooms where these tasks became merely following the rules, usually with little understanding (Squires, op cit).

\section{Our analytical model}

Barmby et al. (2009) provided the researchers with a model. The researchers thought that this model incorporated all the notions of connections and their strengths through reasoning and justification.

The model used the notion that learners should be fluent users of representations. However, the researchers thought that the model would be equally useful for analysing teachers' representations of different mathematical ideas in class. The researchers felt that conceptualising mathematical representations, as Barmby et al. suggested, left an important gap because, whilst it captured weak and strong mathematical reasoning, it did not seem to capture faulty connections or reasoning.

The researchers felt that this was important, especially in the South African context where researchers have identified teachers' understanding of the subject as a problem (Adler, 2009; Harley \& Wedekind, 2004). The researchers hypothesised that one could expect faulty representations of connections. Therefore, they proposed adding a broken line (see Figure 2) to show a faulty representation of a mathematical connection.

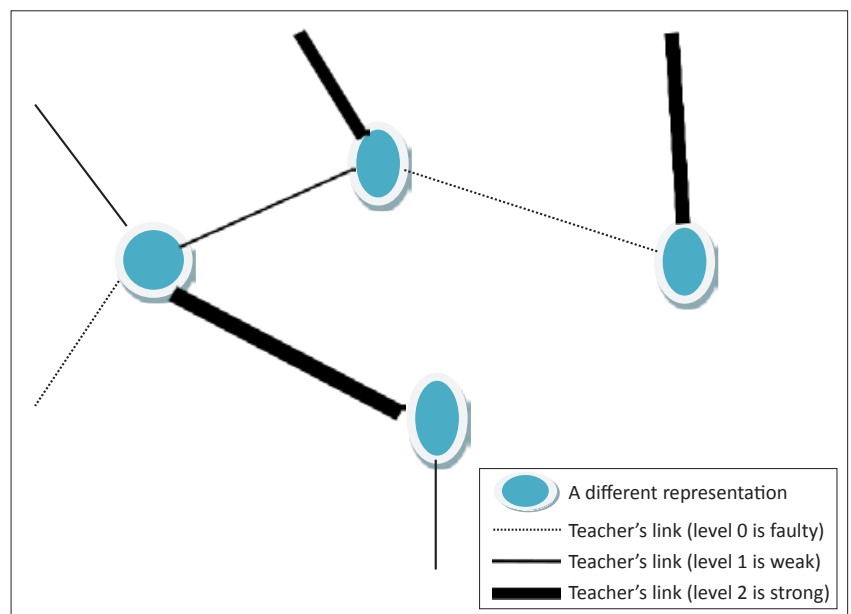

Source: Barmby, P., Harries, T., Higgins, S., \& Suggate, J. (2009). The array representation and primary children's understanding and reasoning in multiplication. Educational Studies in Mathematics, $70(3), 217-241$

FIGURE 2: Representational-reasoning model, adapted from Barmby et al. (2009).
Consequently, they adapted the model slightly so that the mathematical concept or idea (algebraic equation) becomes the alternate representation (symbolic) and the lines show the strength with which the teacher connects or links it to another alternate representation (the graphical representation).

Using this adapted model of representation, broken lines show a faulty representation of a connection, thinner lines show a superficial or weak representation of a connection and thicker lines show a strong or deep representation of a connection. The researchers built on the models of Barmby et al. and of Businskas so that their coding of teacher representations:

- level 0 (DR0) denotes a representation of a mathematical connection in the DR category that was faulty or incorrect

- level 1 (DR1) denotes a representation of a mathematical connection in the DR category that was mathematically correct but superficial or routinely algorithmic, with no further explanation or justification

- level 2 (DR2) denotes a representation of a mathematical connection in the DR category that was more than just mathematically correct; justification and/or further explanation follow.

The researchers give examples of levels of actual representations in the data analysis section of this article.

\section{Methodology}

\section{Sample}

This was a case study involving four Grade 11 mathematics teachers. The researchers made video recordings of each as they taught a series of five algebra-related lessons. These teachers were part of a larger group of teachers who had agreed to take part in a large-scale research project called 'implementing curriculum change in previously disadvantaged communities'.

Whilst some of the participating teachers in the broader study were not qualified to teach mathematics at Further Education and Training (FET) level, the four who provided data for this article were. There were two women and two men teachers. Their teaching experience ranged from 7 to 10 years. The four teachers were from four different schools in previously disadvantaged communities in a Gauteng urban area.

\section{Procedure}

The first author conducted the classroom visits. He observed one teacher teaching Number Patterns and the other three teaching Functions and Algebra.

The decision to observe lessons on these two areas of mathematical content is consistent with the emphasis in the curriculum. It specifically requires teachers to structure learning experiences and situations to develop these key concepts and enable learners to 'experience the power of algebra as a tool to solve problems' (Department of Education, 2003, p. 13).

Star and Rittle-Johnson (2009) also observed that competence in algebra is increasingly being recognised as a critical 
milestone in the journey from primary to high school. International assessments have recorded learners' difficulties in algebra and there is empirical evidence that the transition from arithmetic to algebra is a notoriously difficult one and presents teachers with several challenges (Blum, Galbraith, Henn \& Niss, 2007).

After considering all these factors, the researchers decided to find out what it would mean for teachers to make high quality mathematical connections in an area that the South African national curriculum statement for mathematics (Department of Education, 2003) emphasises but which is so notoriously difficult for both learners and teachers (Koedinger \& Nathan, 2004).

With regard to Number Patterns, Warren and Cooper (2008) posit that the links between patterns and algebra have wide acceptance. Their argument is that learners begin their study of functions in the primary grades as they observe and study patterns in nature and create patterns using concrete models. Learners in high school then expand their knowledge of algebra as they analyse a variety of different types of number patterns.

\section{Validity and reliability}

The analytical tool for this study measured the quality of the mathematical connections that teachers used as they taught certain mathematical concepts in class.

The researchers initially collected pilot data and then tested the tool on the pilot data. During this piloting period, two other mathematics experts (one who sets Grade 12 examinations and one who is a team leader for marking them) validated the tool. The researchers presented the tool at several professional conferences and Doctor of Philosophy $(\mathrm{PhD})$ meetings, where it underwent rigorous peer reviewing before taking its final form.

The researchers addressed the issue of reliability through replication because they observed four different teachers presenting different content. They obtained similar results for the DR0 category as it produced the highest frequencies. Other research results from South Africa (Davis \& Johnson, 2007) and abroad (Ball, 2001) corroborated this. This confirms the prevalence of DR0 representations in practice.

Because the researchers observed only four teachers, one cannot generalise the findings beyond the cases they studied. This is the nature of case studies. However, consistent with the objective of the study, the findings could lay the principles for making high quality mathematical connections in practice.

\section{Ethical considerations}

The Department of Education granted approval to proceed with this study under permit T-728 P01/02 U-848. At institutional level, the university ethics committee granted approval under protocol 2007EC007. At school level, the first author received informed consent from the principals, teachers and parents of the learners who would participate in the study. At both school and individual levels, the researchers maintained the participants' anonymity and confidentiality by using pseudonyms (teacher R, M, T and B) and the video recordings did not focus on either the teachers or the learners.

\section{Data analysis}

The researchers provided six excerpts from the classroom interactions. They coded the teachers' representations of mathematical connections at the three different levels of cognitive demand the article presented earlier.

The researchers coded excerpts 1 and 2 as DR0 (faulty), excerpts 3 and 4 as DR1 (weak, superficial or rote) and excerpts 5 and 6 as DR2 (strong or higher order).

In their analysis of these six excerpts, the researchers showed how they identified the different representations as equivalent or alternate (mathematical connections) in each case then justified why they placed the excerpts at each level of quality. In the broader study of Businskas (2008), from which this article draws, she coded some of these excerpts more than once (i.e. in the same episode it was possible to see a part-whole connection, a generalisation, or an if-then connection). Whilst one expects this in a typical classroom situation, this article does not discuss these other types of connections because it focuses only on alternate and equivalent representations.

\section{Excerpt 1 -Teacher B}

This lesson focused on quadratic functions and on how one determines the gradient of a curve at different points on it. The teacher began by defining the word 'calculus' to the learners:

Teacher: $\quad$ Say for instance I mean it's calculus. It has the word calculate within it. Ok. So we will be calculating something but there are rules that we need to follow.

Comment on excerpt 1: The researchers regarded this as an example of an equivalent representation where the teacher attempted to define calculus by rephrasing it to 'we will be calculating'. She represented the idea of calculus in a different way but in the same verbal mode using different descriptors.

This intended to give the learners an understanding of the mathematical idea (of calculus). This was the only definition the teacher offered as an introduction to the series of lessons that followed.

The researchers contend that, in the context of differential calculus and in the absence of further explanation, this representation is problematic because learners might not differentiate between calculating as any other mathematical operation applies it. It does not offer learners a clear idea of what calculus is as a mathematical concept in the context of differential calculus. Therefore, the researchers coded it DR0. 


\section{Excerpt 2 -Teacher $\mathbf{R}$}

This lesson was on multiplying polynomials. The teacher had given learners different tasks to complete on the board and was summarising the observations.

Teacher: We were finding the products of binomials and trinomials, but look at the first terms in the second expressions [these were quadratic, so the teacher circled $2 a^{2}, a^{2}, 3 x^{2}, 4 a^{2}$ and $\left.b^{2}\right]$. The first term is squared. And if the first term is squared and we multiply it by a binomial, the answer is going to be cubed. The two terms in your answer is going to be cubed. And this introduces us to something else now. The difference between ... How do we conclude this? You have been saying it right now. The difference between two cubes. Let's go to question number 3. Did you do it in your books? Let us look at this question. We are given: $(a+b)\left(a^{2}-a b+b^{2}\right)$. Should we work it out or should we go straight for the answer?

Class: Noooo, let us work it out.

Teacher (after the learners had completed it): What are you saying [names a learner]?

$\begin{array}{ll}\text { Learner: } & \text { The answer is } a^{3}+b^{3} \text {. } \\ \text { Teacher: } & \text { What can you say about the answer? What can } \\ & \text { you say about the expression? What are we going } \\ & \left.\text { to call this product [underlines } a^{3}+b^{3}\right] \text { ? We touched } \\ & \text { this yesterday. It's the difference between... } \\ \text { Class: } & \text { Cubes, squares, terms, trinomials, exponents. } \\ \text { Teacher: } & \left.\text { This term cubed [circles } a^{3}\right] \text { and this term cubed } \\ & \left.\text { [circles } b^{3}\right] \text { So it's a difference between two } \\ & \text { cubes. You got it? Alright. Now we agreed here } \\ & {\left[\text { underlining } a^{3}+b^{3}\right] \text { that this is the difference }} \\ & \text { between two cubes. }\end{array}$

Comment on excerpt 2: This is an example of alternate representation because the teacher is representing an algebraic expression $\left(a^{3}+b^{3}\right)$ verbally as the difference of two cubes.

The researchers saw defining $a^{3}+b^{3}$ as the difference of two cubes as mathematically problematic. Therefore, they coded this as DR0. They contend that learners were unlikely to acquire a mathematically acceptable conceptualisation of the difference of two squares or two cubes with a representation like this. The researchers did not regard this as 'a slip of the tongue' because it occurred often throughout the series of lessons

\section{Excerpt 3 - Teacher $\mathbf{R}$}

In the same series of lessons, on multiplying polynomials, one learner completed her task as follows:

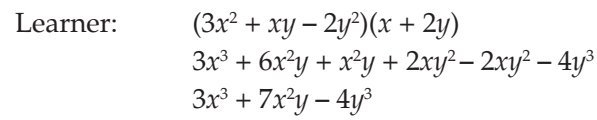

Teacher: What are you saying about her approach? How did she approach this? She was finding the product of binomials and trinomials using the distributive law. Did she apply the distributive law? [The teacher was concerned that the learner 'did not' apply the distributive law correctly because she did not re-arrange the two polynomials with the binomial on the left: $(x+2 y)\left(3 x^{2}+x y-2 y^{2}\right)$. Examples on the board, where the binomial was always on the left hand side and the trinomial on the right hand side, followed. However, in this case the textbook had given the taskwith the trinomial on the left hand side].

Class: Noo [meaning the learner had not applied the distributive law when dealing with this task].

Comment on excerpt 3: The researchers contend that $\left(3 x^{2}+x y-2 y^{2}\right)(x+2 y)$ equals $(x+2 y)\left(3 x^{2}+x y-2 y^{2}\right)$ in terms of the commutative law of multiplication. However, the teacher did not recognise this here. The teacher insisted that the binomial must always be on the left hand side, suggesting that the learners should have rearranged $\left(3 x^{2}+x y-2 y^{2}\right)(x+2 y)$ first before multiplying the polynomials.

Starting with the binomial on the left would achieve the same result (as one would have expected and the lesson proved). The researchers contend that the representation the teacher used here gives a limited conceptual understanding of the distributive law because the teacher associated it with a specific arrangement of the polynomials (binomial to the left and trinomial to the right). Therefore, the researchers regarded it as algorithmic, superficial or rote and coded it DR1.

\section{Excerpt 4 - Teacher T}

This lesson focused on factorising binomials and trinomials.

Teacher: [Writes on the board $\left.-x^{2}+7 x-10\right]$. So today, what we are going to do is factorisation where the first part has a negative coefficient. Are we together? Remember we said that the first number before $x$ is the coefficient. What is the coefficient of $x$ here [points to $\left.-x^{2}\right]$ ?

Class: $\quad 1,-1$ [there is a debate about whether it was 1 or -1, but the teacher finally decided that it was 1].

Teacher: Let's take that coefficient as what 1 . We are saying $1 \times-10$ [the teacher now multiplies this coefficient 1 by the last term -10 in the trinomial and writes -10 on the board]. Remember here we must find the common factors of what, -10 . Which are the common factors of -10 ?

Class: $\quad 5$ and -2 [learners want to give other factors like -5 and 2 , but the teacher discourages them].

Teacher: Let's say they are the same because we just swap the signs. Then, remember when we add those two factors they must give us the $7 x$ [term in the middle of the trinomial]. Which of these two factors will give us $7 x$ ?

\section{Class: $\quad$ None of them.}

Comment on excerpt 4: This is one of the excerpts where the researchers coded other forms of connections (like procedural connections) when dealing with the factors of -10 . However, consistent with their focus in this article, they took the view that, at the point where the teacher says 'let's say they are the same' with reference factors of -10 , he is representing an 
equivalence (i.e. $5 \times-2$ equals $-5 \times 2$ ) after swapping the signs. The product would indeed be -10 in each case.

However, in the context of factorising trinomials, the researchers argue that it was necessary to think about the objective of breaking -10 into its factors. The interest is in factors of the last term -10 that will add to the middle term +7 . Swapping had worked very well before this task because the learners were dealing with tasks where the three terms of the trinomial were positive. Therefore, the factors were also positive. For example, one knows from applying the commutative law of multiplication that $2 \times 5$ equals $5 \times 2$. Similarly, $2+5$ equals $5+2$.

Therefore, suggesting that swapping signs between factors would apply equally in the case of $5 \times-2$ and $-5 \times 2$ is typical of rote learning or applying well-rehearsed procedures without thinking about them.

The researchers coded it DR1. They contend that swapping signs affects their sums, which relates to the middle term when factorising in this context. This task became more confusing because the learners had erroneously interpreted the coefficient -1 of the first term in this particular trinomial as 1 .

\section{Excerpt 5 - Teacher B}

This lesson focused on functions and the different ways of representing them.

Teacher: $\quad$ So now I have written a function: $f(x)=x^{2}+1$. This is what liner or quadratic?

Learner 1: It's quadratic.

Teacher: $\quad$ You are saying it's quadratic How do I identify that this is a linear function and this is a quadratic function? Why are you saying this is quadratic? What if somebody says it is linear?

Class:

It's determined by the exponent of $x$. If $x$ is to the exponent 1 we are talking of a linear function. If it's a square it's quadratic.

Teacher: Okay. It's quadratic. So in order for you to draw this graph what are you going to do?

Learner 2: You can do it in table form.

Teacher: How else can you do it if you did not want to do it in table form?

Learner 3: $\quad$ For some of us with a graphic scientific calculator I can just punch in the function and the calculator can draw the graph for me.

Teacher: [Goes back to the table form]. So we have the function: $f(x)=x^{2}+1$. We are going to substitute the $x$ values into the function and then we will get what, the $y$ values. So we will have [The teacher draws and completes the table with the rest of the class.]

\begin{tabular}{|c|c|c|c|c|c|}
\hline$x$ & -2 & -1 & 0 & 1 & 2 \\
\hline$y$ & 5 & 2 & 1 & 2 & 5 \\
\hline
\end{tabular}

Teacher: Will this help you to draw the graph and if so how?
Learner 4: $\quad$ Yes, it will, by drawing the $x$ - and $y$ - axes then plotting the points.

Teacher: [The teacher asks one child to come to the board]. So show us how to draw the graph. [The teacher then says] We have drawn the graph of $y=x^{2}+1$.

Comment on excerpt 5: The researchers interpreted this as an example of connecting a mathematical idea (quadratic function) using alternate representations (verbal, algebraic, tabular and graphic). In this excerpt, the teacher did not just accept correct answers without explanation or justification. She kept pressing for justification or reasoning from the learners. Examples are 'why quadratic', 'why not linear', 'how else can you do it' and 'will this help'.

Therefore, it is consistent with how the researchers have defined cognitively demanding activities in this article. The researchers coded it DR2.

\section{Excerpt 6 - Teacher M}

This lesson focused on arithmetic or linear sequences within the topic number patterns.

Teacher: Right, suppose you are given a list of numbers starting with [writes 3, 6, 9... on the board]. Somebody, tell me the next number.

Learner 1: 12

Teacher: Somebody else.

Learner 2: 12

Teacher: 12. They all say the next number will be 12 . Anybody who does not agree? [The teacher raises his hand and pauses. After no other responses, the teacher folds his arms]. But, how do we know it's 12? Suppose somebody comes in from a distance and says it's 13 ? Why 12, why not 13 ? [Says learner's name].

Learner 3: They are multiples of three.

Teacher: Okay, somebody tell us what the tenth term will be.

Learner 4: $\quad$ Term 10 will be 30 .

Teacher: Why? How do we know it is going to be 30?

Learner 5: There is a relationship between the term number and the value in this sequence and each time the term number is times 3 to get the term value.

Teacher: $\quad$ So what shall term $n$ be?

Learner 6: $3 n$.

Comment on excerpt 6: Here, the researchers contend that the teacher gave an equivalent representation or connection between a term number $3 n$ and term value 30 in this particular sequence. Recognising this equivalence is important for determining the general term for a sequence. It is also useful for forecasting or predicting unknown term values in the sequence.

Again, the teacher did not just accept correct answers (like 12, 30 or $3 n$ ) without explanation or justification. He insisted on justification or reasoning from the learners ('why 12', 'why 
not 13 ', 'why $30^{\prime}$, 'how do we know' and 'so what will be term $\left.\mathrm{n}^{\prime}\right)$.

Therefore, it is consistent with how the researchers have defined cognitively demanding representations in this article. The researchers coded it DR2.

\section{Summary of findings}

The researchers transcribed 20 lessons and coded 377 teachers' representations in accordance with their coding system. A summary of their observations of the DR category of mathematical connections follows.

Figure 3 gives a comparison of the level of the quality of the representations of mathematical connections of each teacher.

Note that the bars in Figure 3 give data counts and not percentages. For example, in the case of Teacher $M$, the researchers recorded faulty connections (DR0) 11 times. They then converted them to percentages for the discussion.

The different representations were faulty in as high as $60 \%$ of the statements (as for Teacher R), while 30\% of them were rote or routinely algorithmic. This left only $10 \%$ of the representations with the potential to develop a deep understanding of concepts and procedures.

However, Teacher M's representations of mathematical connections fell into level 2 (higher order) in $61 \%$ of the cases and into level 0 (faulty) in only $0.5 \%$ of the cases. This suggests that Teacher $\mathrm{M}$ might have created more opportunities for learners to develop higher quality mathematical connections than did the other teachers.

The researchers did not intend to delve into causal relationships or infer why this was the case. They were specifically interested in describing the nature and quality of teachers' mathematical connections.

Figure 4 gives the summaries for the four teachers.

This graph shows that most of the four teachers' representations of mathematical connections were either faulty (level 0) or superficial (level 1). The differences in the heights of the three bars in Figure 4 might not reveal the magnitude of the problem.

However, when one considers that level 2 of cognitive demand should be the target of classroom practice, then combining the levels 0 and 1 bars reveals a cumulative $70 \%$ off-target in the teachers' representations.

\section{Implications}

Given the findings of the study, the researchers argue that most learners probably lost opportunities to develop a deep understanding of mathematical connections.

The researchers acknowledge the limitations of the study, in terms of its generalisability, because of the small sample.

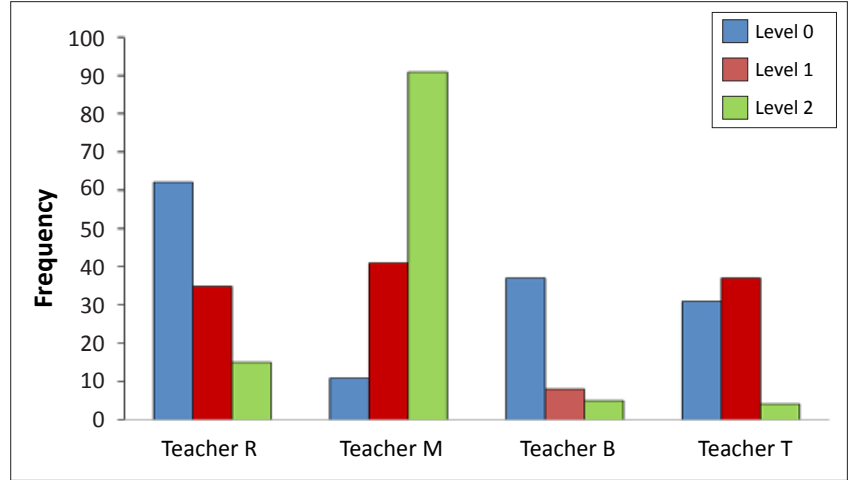

Summaries showing data counts for each teacher $(n=377)$.

FIGURE 3: Comparison of the levels of quality of the representations of each teacher.

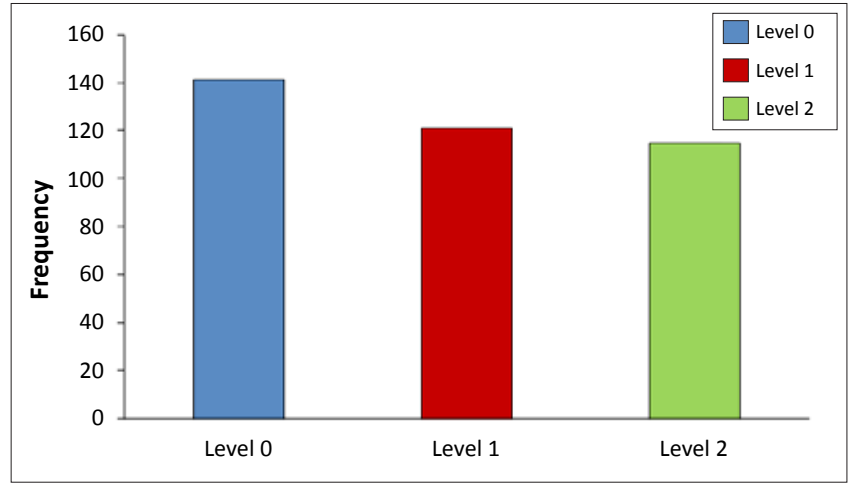

FIGURE 4: Comparison of the quality of the representations.

However, the researchers note that Davis and Johnson (2007) made similar observations: that teachers spent most of classroom time in South Africa on explaining mathematical ideas, principles and definitions. Most teachers 'briefly referred to definitions but without discussing or explicating the mathematical reasons for the productions of the definitions' (p. 123).

Given this consistency in results, the researchers believe that helping teachers to build their representational repertoires, which consists of metaphors, analogies, illustrations, examples, explanations and demonstrations, and with further justification and explanation, might improve the effectiveness of their instructional practices and create opportunities for learners to learn higher order cognitive skills and processes.

\section{Conclusion}

There are developmental lessons that one could learn from this study.

The researchers argue that their results confirm that different representations prevail in different categories or forms of mathematical connections in practice. This is consistent with the literature.

Therefore, they see potential in their results that researchers might want to test further, especially in South African classrooms. So far, researchers seem not to have identified what it means for teachers to enable learners to make strong mathematical connections. 
This could be a possible entry point into teacher support and enrichment programmes.

\section{Acknowledgements}

The researchers thank the Department for International Development for funding the PhD study from which this article draws. The views this article expresses are not necessarily those of the funders.

\section{Competing interests}

The authors declare that they have no financial or personal relationship(s) that might have inappropriately influenced them when they wrote this article.

\section{Authors' contributions}

M.K.M. (Rhodes University) conducted all the research and wrote the manuscript. H.V. (University of the Witwatersrand) was the Implementation of Curriculum Change project leader and made some final conceptual contributions to the manuscript. M.S. (Rhodes University) made initial conceptual contributions.

\section{References}

Adler, J. (2009). A methodology for studying mathematics for teaching. Recherches en Didactique des Mathematiques, 29(1), 33-58.

Andrews, P. (2009). Comparative studies of mathematics teachers' observable learning objectives: validating low inference codes. Educational Studies in Mathematics, 71, 97-122. http://dx.doi.org/10.1007/s10649-008-9165-x

Anthony, G., \& Walshaw, M. (2009a). Characteristics of effective teaching of mathematics: A view from the West. Journal of Mathematics Education, 2(2), 147-164. Available from http://educationforatoz.org/images/_9734_12_Glenda_ Anthony.pdf

Anthony, G., \& Walshaw, M. (2009b). Effective pedagogy in mathematics. In J. Brophy (Ed.),

Educational Practices Series - 19 (pp. 147-164). Belgium: International Academy of Education (IAE).

Ball, D.L. (2001). Teaching, with respect to mathematics and students. In T. Wood, B.S. Nelson, \& J. Warfield (Eds.), Beyond classical pedagogy: Teaching elementary school mathematics (pp. 11-21). Mahwah NJ: Lawrence Erlbaum Associates.

Barmby, P., Harries, T., Higgins, S., \& Suggate, J. (2009). The array representation and primary children's understanding and reasoning in multiplication. Educational Studies in Mathematics, 70(3), 217-241. http://dx.doi.org/10.1007/s10649-0089145-1

Blum, W., Galbraith, P.L., Henn, H.-W., \& Niss, M. (2007). Modelling and applications in mathematics education. New York: Springer. http://dx.doi.org/10.1007/978-0387-29822-1

Businskas, A. (2008). Conversations about connections: How secondary mathematics teachers conceptualise and contend with mathematical connections. Unpublished doctoral dissertation. Simon Fraser University, Burnaby, Canada. Available from http://ir.lib.sfu.ca/handle/1892/10579

Davis, Z., \& Johnson, Y. (2007). Failing by example: Initial remarks on the constitution of school matematics, with special reference to the teaching and learning of mathematics in five seconday schools. In M. Setati, N. Chitera, \& A. Essien (Eds.), Proceedings of the 13th Annual National Congress of the Association for Mathematics Education of South Africa, Vol. 1 (pp. 121-136). White River: AMESA. Available from http://www.amesa.org.za/AMESA2007/Proceedings.htm
Department of Education. (2003). National curriculum statement. Grades 10-12 (General) - Mathematics. Pretoria: Department of Education.

Edwards, N. (2010). An analysis of the alignment of the Grade 12 Physical Sciences examination and the core curriculum in South Africa. South African Journal of Education, 30, 571-590. Available from http://www.sajournalofeducation.co.za/ Education, 30, 571-590. Available from
index.php/saje/article/view/389/221

Gagatsis, A., \& Elia, I. (2004). The effects of different modes of representation on mathematical problem solving. In M.J. Høines, \& A.B. Fuglestad (Eds.), Proceedings of the 28th Conference of the International Group for the Psychology of Mathematics Education, Vol. 2 (pp. 447-454). Bergen: Bergen University College. Availabe from http://www.kurims.kyoto-u.ac.jp/EMIS/proceedings/ PME28/RR/RR171_Gagatsis.pdf

Harley, K., \& Wedekind, V. (2004). Political change, curriculum change and socia formation, 1990 to 2002. In L. Chisholm (Ed.), Changing class: Education and socia change in post-apartheid South Africa (pp. 195-220). Cape Town: HSRC Press.

Hodgson, T.R. (1995). Connections as problem-solving tools. In P.A. House, \& A.F. Coxford (Eds.), Connecting Mathematics across the curriculum (pp. 13-21). Reston, VI: National Council of Teachers of Mathematics.

Koedinger, K.R., \& Nathan, M.J. (2004). The real story behind story problems: Effects of representations on Quantitative Reasoning. Journal of the Learning Sciences, 13(2), 129-164. http://dx.doi.org/10.1207/s15327809jls1302_1

Lolwana, P. (2005, June). Where to with Matric? Paper presented at the Umalus Seminar - Theme - 'Matric what is to be done?', UNISA Senate Hall, Pretoria.

Mhlolo, M.K. (2011). From coherence in theory to coherence in practice: A stock-take of the written, tested and taught National Curriculum Statement for Mathematics (NCSM) at further education and training (FET) level in South Africa. Unpublished doctoral dissertation. University of the Witwatersrand, Johannesburg, South Africa. doctoral dissertation. University of the Witwatersrand, Johannesburg, South Africa.
Available from http://wiredspace.wits.ac.za/bitstream/handle/10539/11274/ Available from $\mathrm{http}: / /$ wiredspace.wits.ac.za/bitstream/handle/
Mhlolo\%20M\%20K\%20PhD $\% 20$ Final\%20Thesis.pdf?sequence $=1$

McDiarmid, G.W., Ball, D.L., \& Anderson, C.W. (1989). Why staying one chapter ahead doesn't really work: Subject specific pedagogy. In M. Reynolds (Ed.), The knowledge base for beginning teachers (pp. 193-205). New York, NY: Paragon Press.

Muller, J. (2005, June). The challenge of cognitive demand. Paper presented the Umalusi Seminar - Theme - "Matric: What is to be done?", UNISA Senate Hall, Pretoria.

Muller, J., \& Subotzky, G. (2001). What knowledge is needed in the new millennium? Organization, 8(2), 163-182. http://dx.doi.org/10.1177/1350508401082004

National Council of Teachers of Mathematics. (2000). Principles and standards for school mathematics. Reston, VA: National Council of Teachers of Mathematics.

Reead, S.K., \& Jazo, L. (2002). Using multiple representations to improve conceptions of average speed. Journal of Educational Computing Research, 27(1/2), 147-166. http://dx.doi.org/10.2190/X56Q-EBFA-AB8B-VHX8

Sierpinska, A. (1996). Understanding in mathematics. London: Falmer Press.

Silver, E.A., Mesa, V.M., Morris, K.A., Star, J.R., \& Benken, B.M. (2009). Teaching mathematics for understanding: An analysis of Irssons submitted by teachers seeking NBPTS Certification. American Educational Research Journal, 46(2) 501-531. http://dx.doi.org/10.3102/0002831208326559

Squires, D.A. (2009). Curriculum alignment: Research-based strategies for increasing student achievement. Thousand Oaks, CA: Corwin Press.

Star, J.R., \& Rittle-Johnson, B. (2009). Making algebra work: Instructional strategies that deepen student understanding, within and between algebraic representations. ERS Spectrum, 27(2), 11-18. Available from http://nrs.harvard.edu/urn-3:HUL. InstRepos:4889486

Stylianou, D.A. (2010). Teachers' conceptions of representation in middle schoo mathematics. Journal of Mathematics Teacher Education, 13, 325-343. http:// dx.doi.org/10.1007/s10857-010-9143-y

Warren, E., \& Cooper, T. (2008). Generalising the pattern rule for visual growth patterns: Actions that support 8 year olds' thinking. Educational Studies in Mathematics, 67, 171-185. http://dx.doi.org/10.1007/s10649-007-9092-2

Weinberg, S.L. (2001, April). Is there a connection between fractions and division? Students' inconsistent responses. Paper presented at the Annual Meeting of the American Educational Research Association, Seattle, WA.

Zurawsky, C. (2006). Do the math: Cognitive demand makes a difference. Research Points, 4(2), 1-4. Available from http://www.aera.net/uploadedFiles/Journals and_Publications/Research_Points/RP_Fall06.pdf 